\title{
Local landscape effects on population dynamics of Ixodes ricinus
}

\author{
Naveed Asghar, ${ }^{1-3}$ Mona Petersson, ${ }^{1}$ Magnus Johansson, ${ }^{1-3}$ Patrik Dinnetz ${ }^{1}$ \\ 'School of Natural Sciences, Technology and Environmental Studies, Södertörn University, \\ Huddinge; ${ }^{2}$ School of Medical Sciences, Örebro University, Örebro; ${ }^{3}$ Inflammatory \\ Response and Infection Susceptibility Centre, Faculty of Medicine and Health, Örebro \\ University, Örebro, Sweden
}

\begin{abstract}
Ixodes ricinus, a common tick in Europe, transmits severe tickborne pathogens (TBPs). In Sweden, both prevalence and incidence of tick-borne infections have increased during the last few decades, and a majority of the cases is reported from the area around Stockholm. Among ticks, transmission of TBPs involves co-feeding of susceptible larvae or nymphs with infected ticks on the same host. Seasonal synchrony of immature stages and total tick abundance are important factors for the probability of horizontal transmission of TBPs. We have studied the association between local landscape characteristics and population dynamics and the probability of co-occurrence of different life cycle stages of I. ricinus at different locations south of Stockholm, Sweden. We found significant spatiotemporal variation in tick activity patterns. Mean tick abundance varied with a tenfold difference among study sites. The probability of co-occurrence of larvae, nymphs and
\end{abstract}

Correspondence: Naveed Asghar, School of Medical Sciences, Orebro University, Campus-USÖ, Örebro, SE-70182, Sweden.

Tel: +46.19302192 - Fax: +46.19303566 .

E-mail: naveed.sh.asghar@sh.se

Key words: Ixodes ricinus; Abundance; Co-occurrence; Vegetation; Sweden.

Contributions: NA, tick sampling and manuscript writing; NA, MP, MJ, PD, study design, data analysis and manuscript reviewing.

Conflict of interest: the authors declare no potential conflict of interest.

Funding: the work was supported by grants to $\mathrm{MJ}$ by the foundation for Baltic and East European studies.

Acknowledgments: the authors are grateful to Mona Insulander, Infectious Disease Unit, Stockholm County Council, for advice about study sites.

Received for publication: 21 April 2016.

Revision received: 14 July 2016.

Accepted for publication: 17 July 2016

(c) Copyright N. Asghar et al., 2016

Licensee PAGEPress, Italy

Geospatial Health 2016; 11:487

doi:10.4081/gh.2016.487

This article is distributed under the terms of the Creative Commons Attribution Noncommercial License (CC BY-NC 4.0) which permits any noncommercial use, distribution, and reproduction in any medium, provided the original author(s) and source are credited. female adults was highest in June and decreased significantly with vegetation height. In addition, the amount of forest habitat and open water in the surrounding landscape of the study sites expressed significant negative effects on tick abundance and co-occurrence, indicating that environmental heterogeneity may increase the likelihood of good rodent habitats, which in turn, are suitable hosts for immature ticks.

\section{Introduction}

Ixodes ricinus (Acari: Ixodidae), a common tick in Europe, has an extremely wide host range including mammals, birds and lizards (Jaenson et al., 1994; Randolph, 2009). I. ricinus is known to transmit many tick-borne pathogens (TBPs), such as Anaplasma phagocytophilum, Rickettsia helvetica, tick-borne encephalitis virus (TBEV) and Borrelia burgdorferi s.l. (Gray, 2002; De La Fuente et al., 2008; Randolph, 2009). Incidence of human cases, and prevalence of TBPs can be proportional to tick abundance (Kantso et al., 2010; Kilpatrick et al., 2014). Over the last years both ticks and TBPs have had a positive development. Both the incidence of tick bite and the burden of disease were reported to double in the Netherlands from 1994 to 2001 (Den Boon et al., 2004). In Scandinavia, an increase in I. ricinus abundance and an expansion of its Northern distribution limit associated with climate change has been reported (Lindgren et al., 2000; Jore et al., 2011; Jaenson et al., 2012). There has also been a marked increase in prevalence and incidence of tick-borne infections in Scandinavia during the last few decades (Skarphedinsson et al., 2005; Jaenson et al., 2012).

An additional risk for humans to be infected by TBPs depends on the horizontal transmission of TBPs among ticks. Co-feeding transmission is well characterised for several TBPs, and probably crucial for the horizontal transmission among ticks (Labuda et al., 1993; Gern and Rais, 1996; Zemtsova et al., 2010). Co-occurrence of infected and non-infected ticks is a sine qua non for TBPs transmission by co-feeding, which in turn has a positive relationship with the density of questing ticks (Burri et al., 2011). Rodents, owing to their small sizes, serve as best hosts for TBPs transmission among co-feeding ticks. Populations of rodents and other small animals are in turn strongly influenced by landscape characteristics. Appearance of I. ricinus in regions previously unrecorded for I. ricinus in Slovakia (Hrk ová et al., 2008) may be linked to restricted cultivation practices that have generated new habitats, both for wild rodents and ticks (Medlock et al., 2013). A shift from cultivated to uncultivated land generates herbaceous and woody vegetation (Sumilo et al., 2008), promoting invasion of rodents and deer as well as ticks. In addition, local populations of small mammals also improve TBPs habitat by sustaining immature tick stages (Medlock $e t$ al., 2013). 
Landscape attributes play a key role in the distribution and transmission of vector-borne pathogens by affecting population dynamics of arthropod vectors and their vertebrate hosts (Lambin et al., 2010; Medlock et al., 2013). Broadleaf woodlands can support high abundances of ticks and their hosts (Dister et al., 1997). However, increased host diversity could potentially reduce tick abundance and the risk of tick-borne infections due to the dilution effect (Ostfeld and Keesing, 2000; Schmidt and 0stfeld, 2001; Logiudice et al., 2003; Keesing et al., 2009). However, this may only be true under exceptional circumstances (Randolph and Dobson, 2012). Habitat fragmentation can reduce vertebrate biodiversity, resulting in species-poor communities with few large hosts which are relatively poor reservoirs of TBPs, and more small mammals (Logiudice et al., 2003; Patz et al., 2004) enhancing the chances for sub-adult ticks to co-feed on competent hosts.

Earlier studies of ticks and TBPs have focused on the generalised effect of landscape variables on tick distribution patterns (Daniel et al., 1998; Randolph, 2000; Lambin et al., 2010; Vanwambeke et al., 2010). A field study regarding local effects of landscape characteristics on the probability of co-occurrence and the dynamics of different tick life cycle stages in time and space is needed. In this case study south of Stockholm, Sweden, we studied the association among biotic and abiotic factors, tick activity and co-occurrence of larvae, nymphs and adult female ticks. In addition, the association between local environmental conditions, landscape characteristics and population dynamics of questing ticks was analysed from site scale $(100 \mathrm{~m})$ to local scale $(1000 \mathrm{~m})$. The main objectives of this study were to analyse if local environmental factors are associated with tick activity, and specifically if they can indicate co-occurrence of larvae, nymphs and adult females. Further, we wanted to analyse if there are discernible landscape characteristics at a scale of up to one $\mathrm{km}$ that are associated with tick activity.

\section{Materials and Methods}

\section{Study area}

The study includes tick sampling from six different sites south of

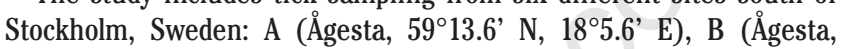

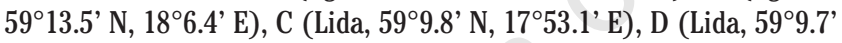
N, $17^{\circ} 52.5^{\prime} \mathrm{E}$ ), E (Flemingsberg, 59 ${ }^{\circ} 13^{\prime} \mathrm{N}, 17^{\circ} 56.3^{\prime} \mathrm{E}$ ) and F (Röda villorna, $59^{\circ} 12.2^{\prime} \mathrm{N}, 17^{\circ} 52.2^{\prime} \mathrm{E}$ ) (Figure 1). Areas A, B, C and D represent sampling sites near popular recreation areas, whereas areas $\mathrm{E}$ and $\mathrm{F}$ represent a forest site and a woodland site near a pasture, respectively. The sampling sites were initially selected based on prior information on TBEV infections at sites C, D and F (personal communication). Tick population dynamics at sites $\mathrm{C}$, D and $\mathrm{F}$ with known TBEV cases were supposed to be compared with A, B and E.

\section{Sampling}

Ticks were sampled at all sites using a slightly modified form of the established blanket dragging technique (Melik et al., 2007), where the head of a dry mop was passed through the stitched end of $75 \times 80 \mathrm{~cm}$ cotton flannel blanket. A tubular steel handle was attached to the mop head via a $360^{\circ}$ swivel. We named the modified method mop-blanket and used it for all tick sampling reported here.

Sampling was started in June 2012 and continued to the beginning of October 2012 with a 4-5 week gap in between each collection. Sampling was performed between 11:00 am and 6:00 pm but avoided during rainy days. At each sampling site we randomly selected ten $3 \times 3$ $\mathrm{m}$ plots for tick sampling. The starting point at each sampling site was selected using a hand-held compass and randomly choosing a direction between $0^{\circ}-360^{\circ}$ by blindly rotating the compass house. Then, we randomly selected a distance between $0-36 \mathrm{~m}$ using the same blind compass rotation technique and walked the selected distance in the selected direction to find the first plot. Later, we used the first plot as starting point for selecting the second plot, and so on. In each plot the blanket was swept over the vegetation with normal walking speed (approximately $1 \mathrm{~m} / \mathrm{s}$ ), using the mop shaft for steering. Right-left and bottomtop sweeps were performed at each plot and ticks were harvested from both sides of the blanket after each sweep. All larvae, nymphs and adults were counted and stored in $15 \mathrm{~mL}$ plastic tubes. At the end of a sampling day all collected ticks were quickly frozen using liquid nitrogen and stored at $-80^{\circ} \mathrm{C}$ for later analysis.

\section{Detection of tick-borne encephalitis virus}

Sampled ticks were analysed for the presence of TBEV using two established TaqMan real time polymerase chain reaction (PCR)-based assays (Schwaiger and Cassinotti, 2003; Gaumann et al., 2010). The established methods target different regions of the TBEV genome, utilise different fluorescent reporters, and differ in sensitivity and specificity.

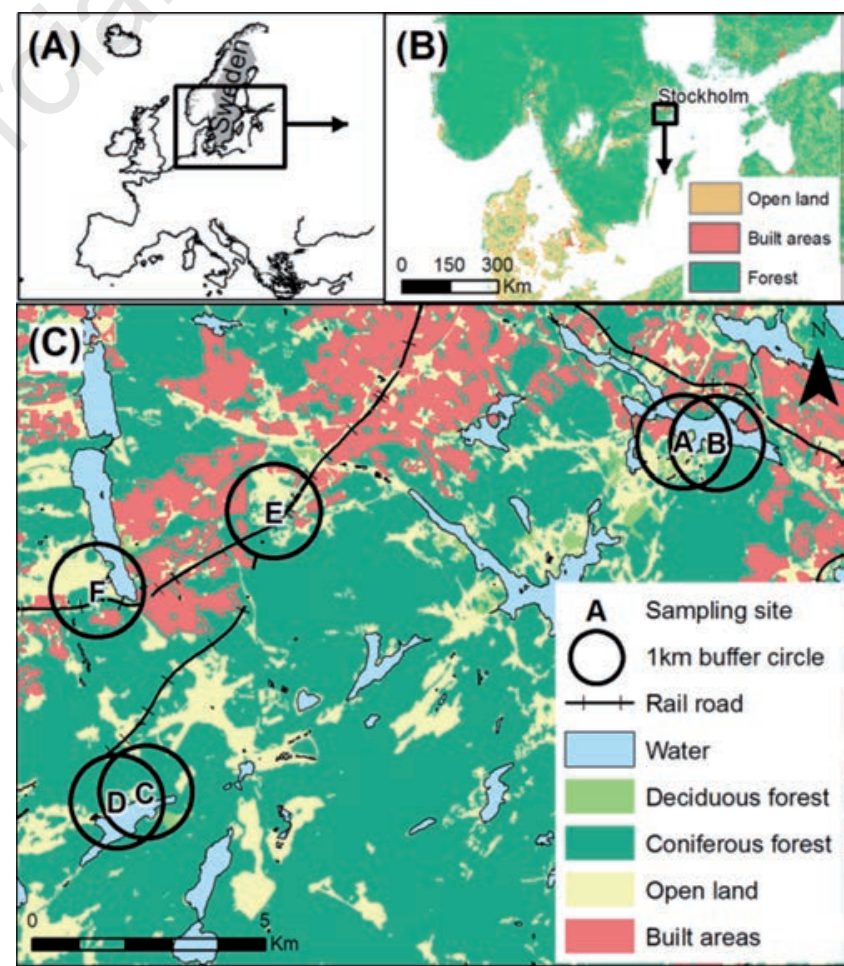

Figure 1. Location of the study area including tick sampling sites [in panel C: Ågesta (A and B), Lida (C and D), Flemingsberg (E), and Röda villorna (F)]. Europe (A), Sweden (B) and tick sampling sites south of Stockholm (C). Map sources: A and B) European Environment Agency CORINE Land Cover data (http://www.eea.europa.eu/publications/COR0-landcover); C) Lantmäteriet Gävle (https://www.lantmateriet.se/), permission I2014/00599. 


\section{Environmental conditions}

At each plot we measured temperature and humidity $5 \mathrm{~cm}$ above soil surface, and vegetation height. In addition, we estimated the light conditions at each plot by taking a photograph upwards, with a camera held approximately $50 \mathrm{~cm}$ above the plot. All photos were analysed using the GNU image manipulation program GIMP, version 2.8.4 (http://www. gimp.org/) to calculate the proportion of pixels not being covered by tree canopies or other shading items. With this sampling design we were able to analyse temporal changes in tick abundances from June to October for all the three-life stages.

For all study sites we used geographical information systems (GIS) to calculate the proportion of different land cover types in concentric subsequent annuli of $100-\mathrm{m}$ increments, within circles with a total radius of $1000 \mathrm{~m}$. Land cover types were measured using a Swedish property map (Lantmäteriet, 2014). We calculated the areas of the land cover types: open land, cultivated fields, coniferous forest, deciduous forest and open water. We estimated the total area in each annulus and calculated proportions for different land cover types for concentric circles with increasing radii from 100 to $1000 \mathrm{~m}$ with an increment of 100 $\mathrm{m}$ for each circle.

\section{Statistical analysis}

We first analysed each life cycle stage separately using linear mixed models with log transformed tick abundance as response variable and time, humidity, temperature, vegetation height and light condition as fixed factors, site as random factor and Gaussian error distribution. Cooccurrence of larvae, nymphs and adult females was analysed as presence/absence per plot using a mixed linear model with the same explanatory variables as above, but with binomial error distribution and logit link. For all models we used the lme4 package (Bates et al., 2013) and R 3.1 (R Core Team, 2013). We started each analysis with a full model including all variables. Using a backward selection procedure with the help of the Akaike information criterion and $P$ values, we selected the most parsimonious and informative models.
Each final model was used as a parent model for testing landscape effects. Once again we used log abundance for all tick lifecycle stages with presence/absence data for co-occurrence as response variables. We tested the main effects from the final models described above and included the proportional coverage of all land cover types with mixed models using the Ime4 package. We made one model for each circle size, from 100 to $1000 \mathrm{~m}$ radii with increments of $100 \mathrm{~m}$. We started with full models with all land cover types and then used backward selection as described above to find the most informative models. All tests were repeated for all circle sizes.

\section{Results}

\section{Tick activity patterns}

A total of 897 I. ricinus including 465 larvae, 382 nymphs, 29 males and 22 females were collected using the mop-blanket technique. Depending on site, the mean tick abundance ranged from 0.1 ticks per $\mathrm{m}^{2}$ at site D to 0.9 ticks per $\mathrm{m}^{2}$ at site E. Temporal fluctuations in tick activity were observed at each sampling site. For larvae and nymphs, peak questing activity was observed in June, whereas adults were mainly active in July (Figure 2). Even though we collected more larvae than nymphs, the mean abundance per month was the highest for nymphs. The reason for this was the clumpy larval distribution with a few plots having extremely high density of larvae and many plots with only a few larvae. Co-occurrence of larvae, nymphs and adult females was the highest in June.

\section{Effect of biotic and abiotic factors}

Temperature was found to have a significant negative effect on questing activity of adults $\left(\chi^{2}=11.191, \mathrm{P}<0.001\right)$. Larvae and nymphs were not significantly affected by temperature, but there was a significant positive relationship between number of questing nymphs and
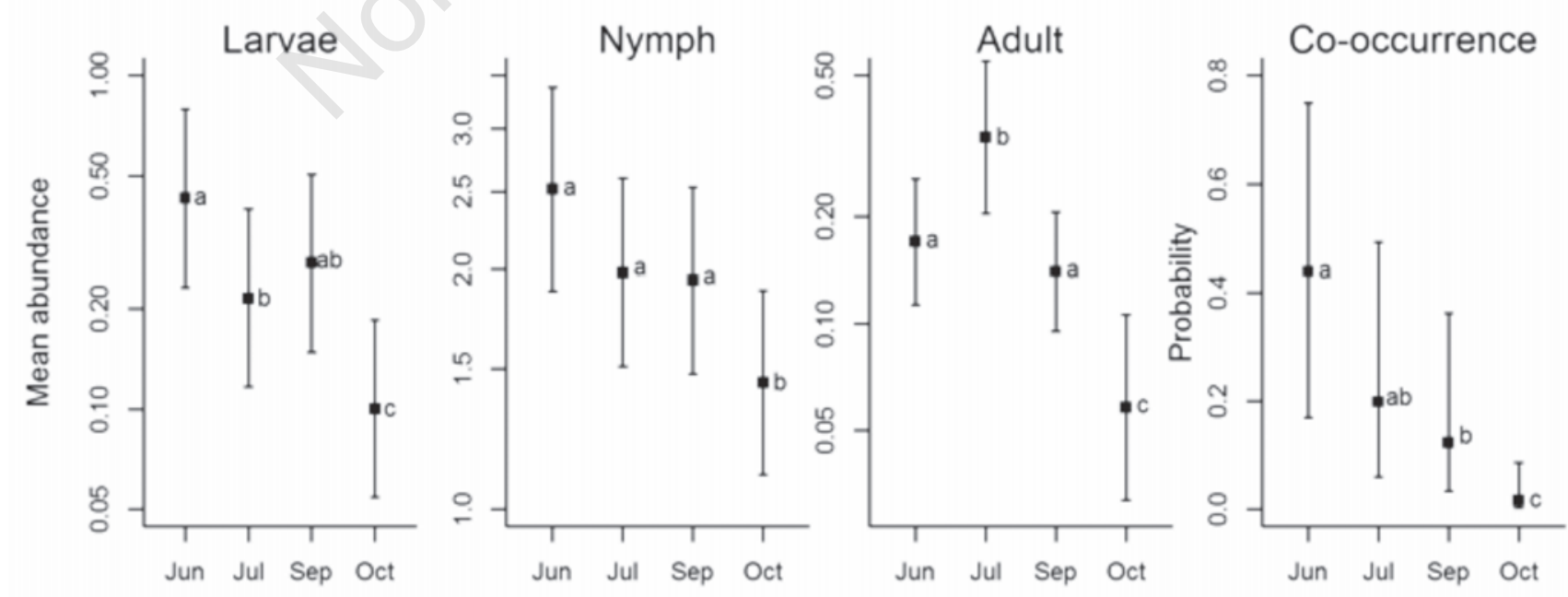

Figure 2. Seasonal variations in questing tick abundance for larvae, nymphs and adults and co-occurrence of host-seeking Ixodes ricinus south of Stockholm. Different letters denote means that are significantly different at $\mathbf{P}<0.05$ (Tukey post-hoc test). 
humidity $\left(\chi^{2}=4.174, \mathrm{P}<0.05\right)$ (Figure 3$)$. In addition, the height of the vegetation significantly affected the number of questing ticks for all three life cycle stages. A decrease in tick abundance was observed with increasing height. Larvae were more strongly affected by this parameter than nymphs (Figure 4A). A statistically significant negative relationship $\left(\chi^{2}=8.995, \mathrm{P}<0.01\right)$ was also observed between height of the surrounding vegetation and co-occurrence of larvae, nymphs, and adult females. No significant effect of light conditions was observed, neither for tick abundance nor for co-occurrence.

\section{Effect of the landscape}

To assess the landscape effect on local tick population dynamics at different landscape scales, we estimated landscape effects in circles of 100 to $1000 \mathrm{~m}$ radii around the sampling sites. The proportion of open land was non-significant in all analyses and was removed from all final models. In general, we found that many individual landscape elements could exhibit negative effects when becoming too common. The effect of landscape characteristics on local tick abundance appeared to diminish at larger distances. The proportions of coniferous and deciduous forests exhibited significant negative effects on both larvae and nymph local abundance up to 700 and $800 \mathrm{~m}$, respectively (Table 1). There was also a significant negative effect by forest surroundings on co-occurrence of larvae and nymphs or larvae and adult females: up to $700 \mathrm{~m}$ for coniferous forest and up to $800 \mathrm{~m}$ for deciduous forest. The abundance of adult females was almost indifferent to the proportion of forest (Table 1). For abundance of larvae, the proportion of water in the landscape was non-significant for the whole range of circle sizes. For the abundance of nymphs and female adults as well as the probability of cooccurrence, there existed significant effects of the proportion of open
(A)

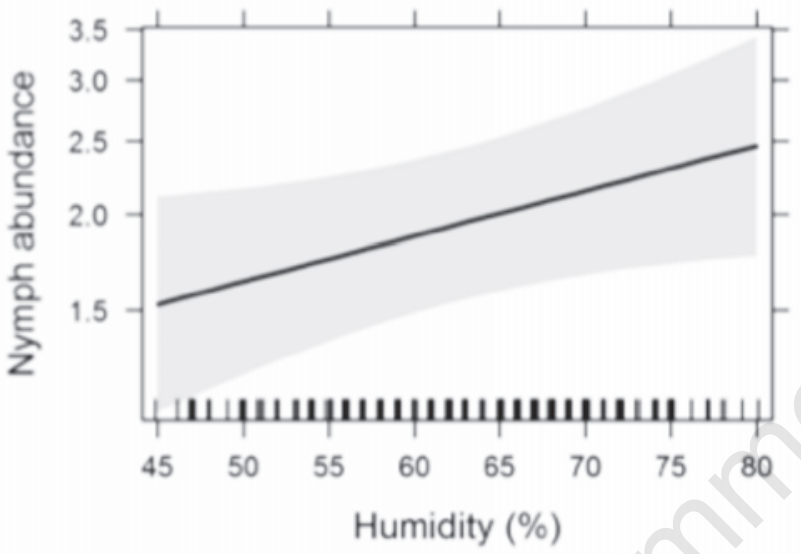

(B)

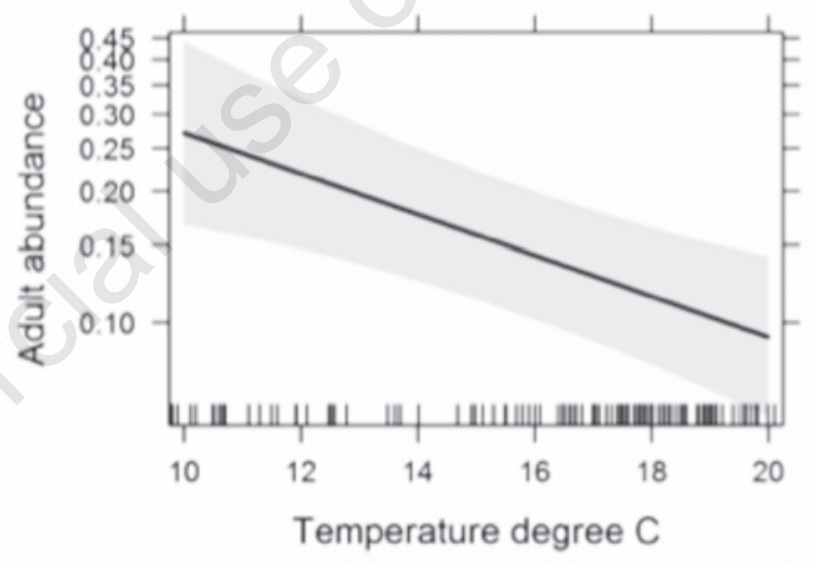

Figure 3. (A) The effect of humidity on nymph abundance $\left(\chi^{2}=4.174, P<0.05\right)$; B $)$ the effect of ambient temperature on abundance of adult ticks $\left(\chi^{2}=11.191, P<0.001\right)$. Grey area indicates $95 \%$ confidence bands.

(A)

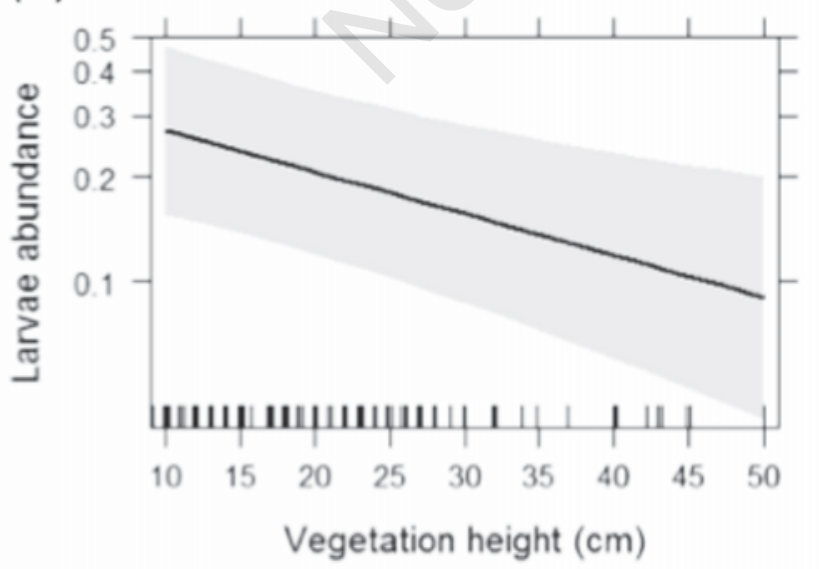

(B)

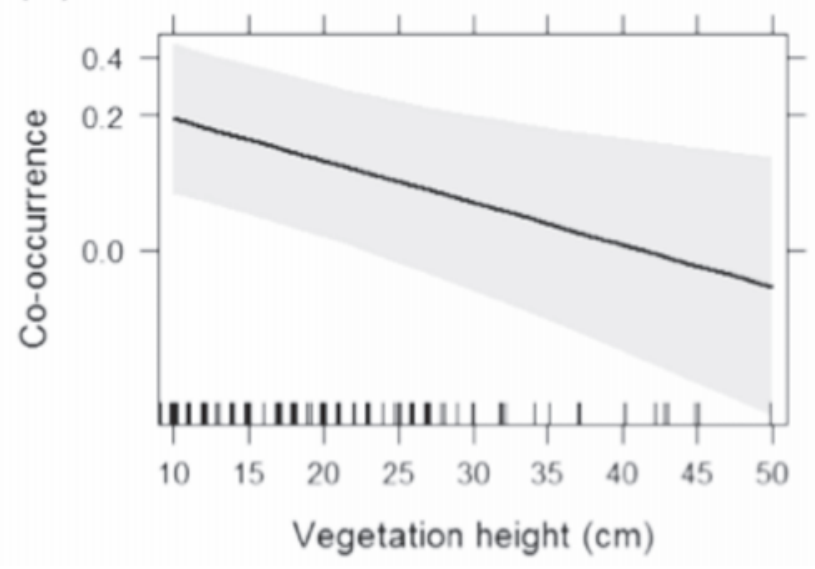

Figure 4. Effects of vegetation height on abundance of larvae (A) and the probability of co-occurrence of larvae and nymphs, larvae and adult females or nymphs and adult females (B). Grey area indicates $95 \%$ confidence bands. 
water in the landscape at small to intermediate circle sizes (Table 1). All effects, except for co-occurrence in the smallest circle, were negative. All effects of the proportion of open water in the landscape on local tick dynamics were lost at distances larger than $600 \mathrm{~m}$ from the sampling sites.

\section{Discussion}

To study tick population dynamics in the field without trapping host animals, our mop-blanket technique is unique. The handle helps to drag the blanket at desired levels and the swivel head facilitates the movement in-between small spaces near the vegetation base, allowing adjustment to local conditions to keep representativeness across sites. The area of each sampling plot was only $3 \times 3 \mathrm{~m}$ due to the fact that the risk of brushing off and dislodgement of ticks from the blanket increase with dragging distance (Estrada-Pena and De La Fuente, 2014). We chose to work at forested sites because this type of vegetation circumvents abrupt fluctuations in temperature and humidity, and favours the abundance of $I$. ricinus (Lindstrom and Jaenson, 2003; Boyard et al., 2011; Dobson et al., 2011).

We found that tick activity changed over the growing season and probability of co-occurrence was twice as high at the beginning of summer compared to later in the season, which might facilitate co-feeding transmission of TBPs early during the vegetation season. It is important to notice that we did not sample for ticks in April and May. In southern Sweden tick activity can peak already in April-May (Bennet $e t$ al., 2006). Irrespective of the starting month, the peak tick activity in the area around Stockholm continues, as we can see in our data, till June. Harrison and Bennett (2012) showed the importance of aggregation of ticks on small rodents for the incidence of Borrelia burgdorferi s.l., and TBEV using a $\mathrm{R}_{0}$ model. In our study, the probability of cooccurrence of larvae, nymphs and female ticks was highest in June and in lower vegetation (Figures 2 and 4B), resulting in enhanced probability of the immature stages to co-occur on rodent hosts. The negative association between questing nymphs and vegetation height has been shown earlier (Gilbert, 2010). In our study this relationship diminishes when ticks develop into later stages. Larvae were strongly negatively affected by high vegetation (Figure 4A), while questing activity of adults was unaffected. However, the sample size for adults is very low and conclusions regarding adult behaviour need to be made with caution. A suitable I. ricinus habitat should provide animal hosts for all questing stages and contain ground vegetation that maintains high humidity to support off-host tick survival. There was a tenfold difference in tick abundance among sites. In general, tick abundance was higher at $\mathrm{B}, \mathrm{F}$ and $\mathrm{E}$ compared to $\mathrm{A}, \mathrm{C}$ and $\mathrm{D}$ (data not shown). The observed difference in tick abundance can be related to landscape attributes and host density (Dobson and Randolph, 2011; Medlock et al., 2013). The large spatial variation in tick abundance is one possible explanation to the observed patchiness of TBEV (Randolph and Dobson, 2012). We did not find TBEV in any of the sampled ticks but a new TBE case was reported at site $\mathrm{E}$ in the fall 2015 . Inability of the PCR assay to detect the virus in the questing ticks can be due to very low virus copy number (Suss et al., 2006) or lack of appropriate temperature required for riboswitch (Elvang et al., 2011). We could not confirm the suggested TBEV distribution based on confirmed cases of TBE,

Table 1. Results from linear mixed models analysing the effect of the amount of coniferous forest, deciduous forest and open water in the surrounding landscape on the abundance of larvae, nymphs and female ticks including co-occurrence of larvae and nymphs or larvae and females.

\begin{tabular}{|c|c|c|c|c|c|c|c|c|c|c|c|c|}
\hline \multirow[t]{2}{*}{ Place } & & & \multicolumn{10}{|c|}{ Radius (m) } \\
\hline & & & 100 & 200 & 300 & 400 & 500 & 600 & 700 & 800 & 900 & 1000 \\
\hline \multirow[t]{8}{*}{ Coniferous forest } & \multirow[t]{2}{*}{ Larvae } & Effect & -0.007 & -0.017 & -0.015 & -0.016 & -0.017 & -0.016 & -0.015 & -0.013 & -0.012 & -0.011 \\
\hline & & & 0.019 & 0.08 & 0.033 & 0.034 & 0.025 & 0.028 & 0.045 & 0.058 & 0.08 & 0.014 \\
\hline & \multirow[t]{2}{*}{ Nymphs } & Effect & -0.006 & -0.019 & -0.016 & -0.016 & -0.016 & -0.015 & -0.013 & -0.012 & -0.011 & -0.011 \\
\hline & & & 0.142 & 0.022 & 0.005 & 0.006 & 0.004 & 0.009 & 0.033 & 0.049 & 0.068 & 0.092 \\
\hline & \multirow{2}{*}{ Co-occurrence } & Effect & -0.02 & -0.086 & -0.075 & -0.08 & -0.008 & -0.007 & -0.05 & -0.044 & -0.04 & -0.037 \\
\hline & & $\mathrm{P}$ & $<0.001$ & $<0.001$ & $<0.001$ & $<0.001$ & $<0.001$ & $<0.001$ & 0.029 & 0.08 & 0.126 & 0.187 \\
\hline & \multirow{2}{*}{ Females } & Effect & 0 & -0.003 & -0.002 & -0.002 & -0.002 & -0.002 & -0.001 & -0.001 & -0.001 & -0.001 \\
\hline & & $P$ & 0.862 & 0.003 & 0.062 & 0.158 & 0.2 & 0.264 & 0.315 & 0.273 & 0.246 & 0.245 \\
\hline \multirow[t]{8}{*}{ Deciduous forest } & \multirow[t]{2}{*}{ Larvae } & Effect & -0.01 & -0.026 & -0.023 & -0.03 & -0.041 & -0.055 & -0.06 & -0.061 & -0.067 & -0.065 \\
\hline & & $P$ & 0.014 & 0.043 & 0.032 & 0.039 & 0.024 & 0.026 & 0.049 & 0.08 & 0.139 & 0.121 \\
\hline & \multirow[t]{2}{*}{ Nymphs } & Effect & -0.009 & -0.027 & -0.023 & -0.028 & -0.037 & -0.049 & -0.051 & -0.052 & -0.055 & -0.051 \\
\hline & & & 0.11 & 0.012 & 0.009 & 0.012 & 0.006 & 0.011 & 0.046 & 0.089 & 0.164 & 0.291 \\
\hline & \multirow[t]{2}{*}{ Co-occurrence } & Effect & -0.059 & -0.155 & -0.153 & -0.203 & -0.269 & -0.339 & -0.328 & -0.313 & -0.321 & -0.284 \\
\hline & & $\mathrm{P}$ & $<0.001$ & $<0.001$ & $<0.001$ & $<0.001$ & $<0.001$ & $<0.001$ & 0.005 & 0.024 & 0.07 & 0.183 \\
\hline & \multirow[t]{2}{*}{ Females } & Effect & 0 & -0.004 & -0.002 & -0.002 & -0.003 & -0.004 & -0.004 & -0.005 & -0.005 & -0.006 \\
\hline & & P- & 0.75 & 0.005 & 0.198 & 0.375 & 0.394 & 0.414 & 0.44 & 0.34 & 0.379 & 0.77 \\
\hline \multirow[t]{8}{*}{ Open water } & \multirow[t]{2}{*}{ Larvae } & Effect & 0.003 & -0.009 & -0.008 & -0.008 & -0.007 & -0.006 & -0.004 & -0.003 & -0.002 & -0.004 \\
\hline & & $P$ & 0.762 & 0.307 & 0.206 & 0.16 & 0.17 & 0.31 & 0.605 & 0.761 & 0.835 & 0.245 \\
\hline & \multirow[t]{2}{*}{ Nymphs } & Effect & 0 & -0.011 & -0.01 & -0.01 & -0.009 & -0.009 & -0.008 & 0.008 & -0.008 & -0.01 \\
\hline & & $\mathrm{P}$ & 0.965 & 0.109 & 0.041 & 0.021 & 0.016 & 0.051 & 0.208 & 0.327 & 0.408 & 0.384 \\
\hline & \multirow[t]{2}{*}{ Co-occurrence } & Effect & 0.015 & -0.04 & -0.032 & -0.032 & -0.03 & -0.023 & -0.019 & -0.02 & -0.023 & -0.034 \\
\hline & & P & $<0.001$ & 0.003 & 0.004 & 0.002 & 0.003 & 0.048 & 0.426 & 0.522 & 0.569 & 0.483 \\
\hline & \multirow[t]{2}{*}{ Females } & Effect & -0.002 & -0.003 & -0.002 & -0.002 & -0.002 & -0.002 & -0.002 & -0.003 & -0.003 & -0.003 \\
\hline & & $P$ & 0.53 & 0.002 & 0.034 & 0.039 & 0.027 & 0.045 & 0.08 & 0.061 & 0.055 & 0.05 \\
\hline
\end{tabular}

Analyses were repeated for 100 to $1000 \mathrm{~m}$ radii circles with increments of $100 \mathrm{~m}$ around sampling sites. 
which might be due to the uncertainty regarding locations where the patients got tick bites.

\section{Conclusions}

Our experiment is not fully optimised for analysing the effect of landscape characteristics on tick abundance because we do not have a random distribution of sites. The study was initially designed to search for TBEV at sites with reported TBE cases and compare TBEV distributions with demographical patterns of $I$. ricinus. Therefore, we tried to match control sites with the cases, but did not manage to find TBEV among any of our sampled ticks. However, our sampling design allows us to compare tick demographical patterns, especially co-occurrence of larvae and nymphs over time, among sites and with landscape patterns as long as we acknowledge that study sites were systematically distributed. Woodland has earlier been reported as a reproducible landscape factor favouring nymph densities in French pastures (Boyard et al., 2011). A study in Central Bohemia showed that TBE risk had a significant positive relationship with deciduous and mixed woodlands, whereas coniferous forest and water bodies had negative effects (Daniel $e t$ al., 1998). Our results show a clear landscape effect for study sites. The amount of coniferous forest, deciduous forest and open water had significant effects on tick abundance, and on co-occurrence of larvae and nymphs. It is also clear that these landscape effects diminish with increasing distance around the sampling sites. Analogous to Daniel $e t$ al. (1998), our results show that open water and coniferous forest have a negative effect on tick abundance. However, contrary to the earlier study (Daniel et al., 1998), the relationship between deciduous forest and tick abundance was negative in our study. Allan et al. (2003) also found a significant decrease in the density of nymphs with increasing area of forest fragments. A possible cause for the negative association may be that both larger forest area and more open water can reduce the available habitat for small rodents, which are prime hosts for the immature ticks (Dobson and Randolph, 2011). This does not explain the negative effects on adult ticks, but the abundance of adult ticks is indeed a consequence of the abundance of the immature stages. An interesting result from our study is that all landscape effects declined rather quickly, and that the effect was lost at a distance of less than one $\mathrm{km}$. Our findings suggest that one need to be careful not to overestimate results from local studies of tick population dynamics and not to generalise to regional spatial scales. Further studies concerning host biodiversity, randomised sampling and extended sampling periods will help to better understand the complex dynamics of ticks and TBPs.

\section{References}

Allan BF, Keesing F, Ostfeld RS, 2003. Effect of forest fragmentation on lyme disease risk. Conserv Biol 17:267-72.

Bates D, Maechler M, Bolker B, Walker S, 2013. Ime4: Linear mixedeffects models using Eigen and S4, p. R package.

Bennet L, Halling A, Berglund J, 2006. Increased incidence of Lyme borreliosis in southern Sweden following mild winters and during warm, humid summers. Eur J Clin Microbiol 25:426-32.

Boyard C, Barnouin J, Bord S, Gasqui P, Vourc'h G, 2011. Reproducibility of local environmental factors for the abundance of questing Ixodes ricinus nymphs on pastures. Ticks Tick Borne Dis 2:104-10.

Burri C, Bastic V, Maeder G, Patalas E, Gern L, 2011. Microclimate and the zoonotic cycle of tick-borne encephalitis virus in Switzerland. J Med Entomol 48:615-27.

Daniel M, Kolar J, Zeman P, Pavelka K, Sadlo J, 1998. Predictive map of Ixodes vicinus high-incidence habitats and a tick-borne encephalitis risk assessment using satellite data. Exp Appl Acarol 22:417-33.

De La Fuente J, Estrada-Pena A, Venzal JM, Kocan KM, Sonenshine DE, 2008. Overview: ticks as vectors of pathogens that cause disease in humans and animals. Front Biosci 13:6938-46.

Den Boon S, Schellekens JF, Schouls LM, Suijkerbuijk AW, Docters Van Leeuwen B, Van Pelt W, 2004. [Doubling of the number of cases of tick bites and lyme borreliosis seen by general practitioners in the Netherlands]. [Article in Dutch]. Ned Tijdschr Geneeskd 148:66570.

Dister SW, Fish D, Bros SM, Frank DH, Wood BL, 1997. Landscape characterization of peridomestic risk for Lyme disease using satellite imagery. Am J Trop Med Hyg 57:687-92.

Dobson ADM, Randolph SE, 2011. Modelling the effects of recent changes in climate, host density and acaricide treatments on population dynamics of Ixodes ricinus in the UK. J Appl Ecol 48:102937.

Dobson ADM, Taylor JL, Randolph SE, 2011. Tick (Ixodes ricinus) abundance and seasonality at recreational sites in the UK: hazards in relation to fine-scale habitat types revealed by complementary sampling methods. Ticks Tick Borne Dis 2:67-74.

Elvang A, Melik W, Bertrand Y, Lonn M, Johansson M, 2011. Sequencing of a tick-borne encephalitis virus from Ixodes ricinus reveals a thermosensitive RNA switch significant for virus propagation in ectothermic arthropods. Vector Borne Zoonotic Dis 11:649-58.

Estrada-Pena A, De La Fuente J, 2014. The ecology of ticks and epidemiology of tick-borne viral diseases. Antivir Res 108:104-28.

Gaumann R, Muhlemann K, Strasser M, Beuret CM, 2010. Highthroughput procedure for tick surveys of tick-borne encephalitis virus and its application in a national surveillance study in Switzerland. Appl Environ Microb 76:4241-9.

Gern L, Rais 0, 1996. Efficient transmission of Borrelia burgdorferi between cofeeding Ixodes ricinus ticks (Acari: Ixodidae). J Med Entomol 33:189-92.

Gilbert L, 2010. Altitudinal patterns of tick and host abundance: a potential role for climate change in regulating tick-borne diseases? Oecologia 162:217-25.

Gray JS, 2002. Biology of Ixodes species ticks in relation to tick-borne zoonoses. Wien Klin Wochenschr 114:473-8.

Harrison A, Bennett NC, 2012. The importance of the aggregation of ticks on small mammal hosts for the establishment and persistence of tick-borne pathogens: an investigation using the R-0 model. Parasitology 139:1605-13.

Hrk ová G, Nováková M, Chytra M, Kostova CBP, 2008. Monitoring the distribution and abundance of Ixodes ricinus ticks in relevance of climate change and prevalence of Borrelia burgdorferi sensu lato in Northern Slovakia (Liptovska valley). Folia Vet 52:62-3.

Jaenson TG, Jaenson DG, Eisen L, Petersson E, Lindgren E, 2012. Changes in the geographical distribution and abundance of the tick Ixodes ricinus during the past 30 years in Sweden. Parasites Vectors 5:8.

Jaenson TG, Talleklint L, Lundqvist L, Olsen B, Chirico J, Mejlon H, 1994. Geographical distribution, host associations, and vector roles of ticks (Acari: Ixodidae, Argasidae) in Sweden. J Med Entomol 31:240-56.

Jore S, Viljugrein H, Hofshagen M, Brun-Hansen H, Kristoffersen AB, Nygard K, Brun E, Ottesen P, Saevik BK, Ytrehus B, 2011. Multisource analysis reveals latitudinal and altitudinal shifts in range of 
Ixodes ricinus at its northern distribution limit. Parasites Vectors 4:84.

Kantso B, Svendsen CB, Jensen PM, Vennestrom J, Krogfelt KA, 2010. Seasonal and habitat variation in the prevalence of Rickettsia helvetica in Ixodes ricinus ticks from Denmark. Ticks Tick Borne Dis 1:101-3.

Keesing F, Brunner J, Duerr S, Killilea M, Logiudice K, Schmidt KA, Vuong H, Ostfeld RS, 2009. Hosts as ecological traps for the vector of Lyme disease. P Roy Soc Lond B Bio 276:3911-9.

Kilpatrick HJ, Labonte AM, Stafford KC, 2014. The relationship between deer density, tick abundance, and human cases of lyme disease in a residential community. J Med Entomol 51:777-84.

Labuda M, Jones LD, Williams T, Danielova V, Nuttall PA, 1993. Efficient transmission of tick-borne encephalitis-virus between cofeeding ticks. J Med Entomol 30:295-9.

Lambin EF, Tran A, Vanwambeke S0, Linard C, Soti V, 2010. Pathogenic landscapes: interactions between land, people, disease vectors, and their animal hosts. Int J Health Geogr 9:54.

Lantmäteriet, 2014. GSD property map, permission I2014/00599. Available from: https:/www.lantmateriet.se/

Lindgren E, Talleklint L, Polfeldt T, 2000. Impact of climatic change on the northern latitude limit and population density of the diseasetransmitting European tick Ixodes ricinus. Environ Health Persp 108:119-23.

Lindstrom A, Jaenson TG, 2003. Distribution of the common tick, Ixodes ricinus (Acari: Ixodidae), in different vegetation types in southern Sweden. J Med Entomol 40:375-8.

Logiudice K, Ostfeld RS, Schmidt KA, Keesing F, 2003. The ecology of infectious disease: effects of host diversity and community composition on Lyme disease risk. P Natl Acad Sci USA 100:567-71.

Medlock JM, Hansford KM, Bormane A, Derdakova M, Estrada-Pena A, George JC, Golovljova I, Jaenson TG, Jensen JK, Jensen PM, Kazimirova M, Oteo JA, Papa A, Pfister K, Plantard 0, Randolph SE, Rizzoli A, Santos-Silva MM, Sprong H, Vial L, Hendrickx G, Zeller H, Van Bortel W, 2013. Driving forces for changes in geographical distribution of Ixodes ricinus ticks in Europe. Parasites Vectors 6:1.

Melik W, Nilsson AS, Johansson M, 2007. Detection strategies of tickborne encephalitis virus in Swedish Ixodes ricinus reveal evolutionary characteristics of emerging tick-borne flaviviruses. Arch Virol 152:1027-34.
Ostfeld R, Keesing F, 2000. The function of biodiversity in the ecology of vector-borne zoonotic diseases. Can J Zool 78:2061-78.

Patz JA, Daszak P, Tabor GM, Aguirre AA, Pearl M, Epstein J, Wolfe ND, Kilpatrick AM, Foufopoulos J, Molyneux D, Bradley DJ, Dis WGLUC, 2004. Unhealthy landscapes: policy recommendations on land use change and infectious disease emergence. Environ Health Persp 112:1092-8

R Core Team, 2013. R: A language and environment for statistical computing. Available from: https://www.r-project.org/

Randolph SE, 2000. Ticks and tick-borne disease systems in space and from space. Adv Parasit 47:217-43.

Randolph SE, 2009. Tick-borne disease systems emerge from the shadows: the beauty lies in molecular detail, the message in epidemiology. Parasitology 136:1403-13.

Randolph SE, Dobson AD, 2012. Pangloss revisited: a critique of the dilution effect and the biodiversity-buffers-disease paradigm. Parasitology 139:847-63.

Schmidt KA, 0stfeld RS, 2001. Biodiversity and the dilution effect in disease ecology. Ecology 82:609-19.

Schwaiger M, Cassinotti P, 2003. Development of a quantitative realtime RT-PCR assay with internal control for the laboratory detection of tick borne encephalitis virus (TBEV) RNA. J Clin Virol 27:136-45.

Skarphedinsson S, Jensen PM, Kristiansen K, 2005. Survey of tickborne infections in Denmark. Emerg Infect Dis 11:1055-61.

Sumilo D, Bormane A, Asokliene L, Vasilenko V, Golovljova I, AvsicZupanc T, Hubalek Z, Randolph SE, 2008. Socio-economic factors in the differential upsurge of tick-borne encephalitis in Central and Eastern Europe. Rev Med Virol 18:81-95.

Suss J, Klaus C, Diller R, Schrader C, Wohanka N, Abel U, 2006. TBE incidence versus virus prevalence and increased prevalence of the TBE virus in Ixodes ricinus removed from humans. Int J Med Microbiol 296(Suppl.40):63-8.

Vanwambeke SO, Sumilo D, Bormane A, Lambin EF, Randolph SE, 2010. Landscape predictors of tick-borne encephalitis in Latvia: land cover, land use, and land ownership. Vector Borne Zoonotic Dis 10:497-506.

Zemtsova G, Killmaster LF, Mumcuoglu KY, Levin ML, 2010. Co-feeding as a route for transmission of Rickettsia conorii israelensis between Rhipicephalus sanguineus ticks. Exp Appl Acarol 52:383-92. 